\title{
Post occupancy evaluation of primary schools in Saudi Arabia
}

\author{
Sana Omari ${ }^{\mathrm{a},}$, Andree Woodcock ${ }^{\mathrm{b}}$ \\ ${ }^{\mathrm{a}}$ Dar Al-Hekma College, Saudi Arabia \\ ${ }^{\mathrm{b}}$ Centre of Excellence in Product and Automotive Design, Department of Industrial Design, Coventry School of \\ Art and Design Coventry University, Coventry, UK.
}

\begin{abstract}
The physical school environment has been shown to be important in helping children fulfill their academic potential and in providing appropriate working conditions for staff. However, few tools have been developed that enable multi stakeholder consultation which takes into account the opinions of young students. In Saudi Arabia there has been widespread investment in schools, but few guidelines have been provided to assist design or continuous evaluation. A Post Occupancy Evaluation (POE) method was developed and used to evaluate three international primary schools in Saudi Arabia. The methods identified weaknesses in the three schools and differences in responses from the three groups consulted (children, teachers and parents). Conclusions drawn from the study are that greater efforts need to be made to draw together research about how school facilities can support teaching and learning, increase effectiveness and levels of satisfaction. POE, when used in conjunction with checklists could be used as a means of driving up standards of educational facilities
\end{abstract}

Keywords: Educational ergonomics, schools

\section{Introduction}

The built environment has been shown to have a direct impact on student achievement and to facilitate teaching and learning. Environmental conditions such as building age, heating, lighting, air quality, noise, use of colour, type of furnishing, room layout and density have all been associated with significant, measurable changes in student attainment and performance (for a review see [1]).

However, in some cases designs are only evaluated by visiting 'experts', who may be unfamiliar with the school and the day-to-day, lived experience of the school by its occupants. Children are seldom regarded as experts who are able to comment on their environment [2]. To this end, [3] developed a Post Occupancy Evaluation toolset (2010) which provided a multistakeholder approach to understanding the experience of primary schools by children, teachers, administrative and catering staff and parents. However, this was not linked to specific, independently assessed design features such as the adequacy of the learning environments. This research addresses the shortcoming in the previous work by using accredited Design Checklists as a means of further assessing the quality of the educational facilities in terms of teaching and learning. This enables triangulation of data, and eases the precision of recommendations.

Saudi Arabia is facing high growth rates in population, educational literacy, facility and technological development. The number of school students has risen from 147226 in 1990 to over 2 million in 1998. The students and their parents have greater demands and expectations when the power of education is realized. In order to meet these demands, it is beholden on educational providers to use the latest research to inform curriculum and facility design. Post Occupancy Evaluation (POE) plays a part in this by enabling building assessments to be made which can guide facility construction and renovations.

The Educational Planning Board, in Saudi Arabia, stated their aims for 2004 as being to design and execute projects such as the construction and renovation of educational buildings. At the time of the research (2010) these aims had not been achieved. The wider aim of this research was therefore to recom- 
mend to the Saudi Arabian Ministry of Education that POE could inform the renovation of existing, and the design of new, state-of-the-art facilities.

\section{Aims}

1. To develop a method that could be used for the evaluation of primary school facilities in Saudi Arabia.

2. To assess the educational facilities of three 'representative' international primary schools using the proposed method.

3. To make recommendations to the schools based on the findings of the study.

\section{Design checklists and Post Occupancy Evaluation}

Frameworks have been developed to enable educational facilities to be evaluated in terms of the extent to which they successfully facilitate learning and teaching. These include those developed by the Council of Educational Facility Planners International (CEFPI), and in the UK, the Commission for Architecture and the Built Environment (CABE) and Department for Education and Society's Exemplar models. Such checklists can be used by experts to assess the presence and adequacy of different facilities.

POEs complement design checklists by aiding in the evaluation of schools once they have been occupies. They should "describe, interpret and explain the performance of a school building" [4,p7]. [5] summarizes their benefits as including enhancing communication among stakeholders, quality monitoring, supporting fine-tuning and the renovation of existing settings and accelerating organizational learning. POEs have been used successfully in a number of countries such as Scotland, UK, U.S.A., Canada, Germany, Brazil, Portugal and New Zealand.

Despite this [6] commented that in reality only a small fraction of school buildings are evaluated against the educational needs of the students and teachers. Building assessment relies predominantly on the judgment of "experts" as to the success or otherwise of a school building. The research reported here takes as its premise that those who are most expert are the end-users. As [6;p8] says: " $A$ key issue is whose judgements should be sought in an assessment.
There is a tendency to regard expert opinion as always more reliable and correct. For many aspects of the environment, the experts are the people who know most about using it - the user."

Therefore the POE toolkit used in this research aimed to position the children and adults (teachers and parents) who use the school as experts. The results of the application of pre-existing design checklists were used as a means of contextualizing (and verifying) user statements, so closing the gap between different forms of appraisal.

\section{Overview of approach}

The research was conducted in three stages; commencing with a familiarization of the three schools, through guided tours, interviews with teachers and a weeklong observation. After this, in Stage 2, the design checklists were completed by Omari, to assess the presence and adequacy of different educational facility design features. In the final stage of the research the POE itself was conducted with teachers, children and parents.

\section{Research instruments}

\subsection{Design checklists}

Four checklists were used to provide a comprehensive assessment of the formal and informal teaching and learning facilities offered by each school. The first author, herself a designer, assessed each of the schools using the checklists.

1. Design Assessment Scale of Elementary schools (DASE) - developed by [7] to measure various aspects of primary school learning environments.

2. Council of Educational Facility Planners International Educational Adequacy Assessment tool [8and 9] to assess the educational adequacy of school buildings.

3. Nair's 28 Design Patterns [10] which provides a comprehensive set of design principles that define best practice

4. Learning Modalities for Classrooms [11]. This instrument allows a measurement to be made of the extent to which the classroom accommodates the 18 learning modalities. 


\subsection{Post Occupancy Evaluation}

\subsubsection{Workbook for young students}

[5] designed a workbook for children, aged 7 to 11 years of age in which a set of cartoon characters were shown in a variety of situations and activities that children would encounter throughout the school day, and which they were asked to comment on. The instrument was categorized into 14 sections questioning students on their school, lunchtime, PE, classrooms, art, science, home time, library, ICT, shared areas, toilet, playgrounds and assembly. The questions were accompanied by a series of simple adjectives that allowed positive or negative responses to be made about areas of the school. Text boxes allowed children to write comments, draw maps of the school and visually represent their understanding of places of significance. This was given to children to complete during class

\subsubsection{Questionnaire for staff and parents}

The questionnaire was a composite of assessment tools developed by 5,10 and 11 and adapted for the Saudi culture. It consisted of 117 Likert scale questions and focused on the educational adequacy and quality of academic learning spaces, specialized learning spaces, support space, cleanliness and maintenance, building features, safety and security, classroom workspace. The parents were only required to fill in the section relating to overall building features.

\section{School sample}

The study took place in three, English speaking, international, primary schools in Saudi Arabia which serve the expatriate community with a small percentage of local students. Unfortunately it was not possible to work in local Saudi private schools, or government schools, as these do not allow visitors, have strict policies against photography, are segregated, and are conducted in Arabic. Working in these schools would require the evaluation to be conducted by third parties. The selected schools were expected to have better educational facilities and could therefore act as a benchmark for local schools.

Data collection occurred over four months, with approximately three weeks spent in each school. The schools were built between 1955 and 2001, had an average enrolment of 1216 children, with average primary school enrolment of 443 children. Classes were selected by the school. 38 teachers were inter- viewed in Stage 1. In Stage 2, 51 teachers, 73 parents and 334 Key Stage 2 children completed the POE

\section{Results}

\subsection{From the checklists}

The results from both the checklists and the POEs were analyzed separately for each school and each stakeholder group so that specific recommendations could be made to each school. Pooling the data from the three schools was not possible owing to the large variance in the quality and quantity of educational facilities. However, the data derived from the checklists for each school was internally consistent and in accordance with the views expressed by both the teachers and parents in the questionnaire and adhoc interviews.

Table 1: Overview of initial impressions for each school

\begin{tabular}{|l|c|l|l|}
\hline \multirow{2}{*}{ Criteria } & \multicolumn{3}{|c|}{ School } \\
\cline { 2 - 5 } & B & A & M \\
\hline Building is in good condition & $\checkmark$ & $\mathbf{x}$ & $\mathbf{x}$ \\
\hline Neat and clean & $\checkmark$ & $\checkmark$ & $\checkmark$ \\
\hline Student work displayed & $\checkmark$ & $\checkmark$ & $\mathbf{x}$ \\
\hline Pictures display various ethnic groups & $\checkmark$ & $\mathbf{x}$ & $\mathbf{x}$ \\
\hline $\begin{array}{l}\text { Displays depict both boys and girls } \\
\text { doing various activities }\end{array}$ & $\checkmark$ & $\mathbf{x}$ & $\mathbf{x}$ \\
\hline Announcements of activities & $\checkmark$ & $\mathbf{x}$ & $\mathbf{x}$ \\
\hline $\begin{array}{l}\text { Building is flexible including large open } \\
\text { spaces, small multi-functional spaces }\end{array}$ & $\checkmark$ & $\mathbf{x}$ & $\mathbf{x}$ \\
\hline Moveable furniture throughout school & $\checkmark$ & $\checkmark$ & $\checkmark$ \\
\hline $\begin{array}{l}\text { Quiet places for individuals and, groups } \\
\text { to withdraw/relax e.g. lounges }\end{array}$ & $\mathbf{x}$ & $\mathbf{x}$ & $\mathbf{x}$ \\
\hline $\begin{array}{l}\text { Identified places where students can be } \\
\text { noisy and do physical activity }\end{array}$ & $\checkmark$ & $\mathbf{x}$ & $\mathbf{x}$ \\
\hline $\begin{array}{l}\text { Plenty of room in corridors/classrooms } \\
\text { to move from one to the other }\end{array}$ & $\checkmark$ & $\mathbf{x}$ & $\mathbf{x}$ \\
\hline Outdoor space for science projects etc & $\mathbf{x}$ & $\mathbf{x}$ & $\mathbf{x}$ \\
\hline $\begin{array}{l}\text { Students responsible for upkeep and } \\
\text { appearance of their school, }\end{array}$ & $\mathbf{x}$ & $\mathbf{x}$ & $\mathbf{x}$ \\
\hline Privacy in bathrooms through doors & $\checkmark$ & $\checkmark$ & $\checkmark$ \\
\hline $\begin{array}{l}\text { Privacy in changing rooms through cur- } \\
\text { tains }\end{array}$ & $\mathbf{x}$ & na & na \\
\hline TOTAL (out of 15) & $\mathbf{1 2}$ & $\mathbf{4}$ & $\mathbf{3}$ \\
\hline
\end{tabular}


Table 1 illustrates the variation in facilities in the three schools as assessed by the checklists. The results suggested that overall circulation patterns were weak, pathways and promenades poorly connected and the schools had few focal points. A number of more general issues emerged across all schools such as:

- Lack of outdoor learning areas, no living views or landscape for imaginative play.

- Poor provision of study areas or personal spaces to cater to multiple intelligences

- Classrooms that lacked variety and flexibility

- Lack of concern about informal learning and support areas.

- Lack of provision for children with special educational needs

School M scored the lowest in most categories. It did not accommodate different learning modalities; the provision of its academic learning areas was rated at $22.3 \%$, specialized learning spaces $11.3 \%$, support areas at $12.3 \%$ and building features at $45 \%$. These results imply that the size, location, quality of furnishings and equipment, the ability to permit change and cater to the educational program were not met. The school also failed to provide satisfactory dining areas, library, playground, gym, auditorium, internet facilities and storage. The facilities that were present were rated at $44 \%$ (with a benchmark attainment needed of $60 \%$ ). School B's facilities were consistently rated at above $75 \%$ except for library and ICT provision at $46.7 \%$ and $50 \%$ respectively.

It may be concluded from the checklists that the schools did not provide an adequate range of rich, varied teaching environments and in their provision of informal, play and social areas. The checklists provided valuable information to the schools, and the results triangulated well. However, all checklists were administered by one person, who acted as an expert, with no prior knowledge of the schools except for a week long observation period. The next part of the research sought to validate the results from a user's perspective.

\subsection{From the questionnaires}

\subsubsection{Teachers issues}

Teachers were mostly dissatisfied with two particular factors within the learning areas. The first being lack of resources and supplies and that learning areas did not cater to instructional needs. This implies that the school layout and design does not provide for the appropriate number of storage, resource areas, tech- nology, equipment and communication facilities. All of these need to be considered prior to construction.

Secondly, the majority of teachers were dissatisfied with the aesthetics and colour of the overall building. teachers at School B were more concerned that the aesthetics be more child appropriate with brighter cheerful colours and that landscape needed to be integrated into the school grounds to make it more welcoming and relaxing for children. Due to the fact that the other two schools had several short comings, lack of facilities and basic needs, the teachers were more concerned with the difficulties they faced due to this and how it hindered their ability to work as professionals. They focused on functionality and adequacy of their learning areas and the need to renovate the school for a new and more functional facility. Students at these schools also focused on the lack of facilities and how it hindered their ability to learn.

\subsubsection{Student issues}

Classrooms were of a particular concern, where both students and teachers felt that display, user needs, storage and temperature were ignored and inadequate and that areas for interaction or socializing were lacking.

Students in all schools were dissatisfied with their cafe, rating this as being an unpleasant and unattractive place to eat and this too was verified by the POE results of the teachers. Students from all three schools (but especially Schools A and M) were generally dissatisfied with the restroom facilities.

With regard to ergonomic issues, it was clear that students and teachers perception of noise was different. For example, at School B 53\% of the students complained of noisy classrooms, but only $17 \%$ of the teachers felt the same way. Both teachers and students in the other two schools complained that noise was a concern, but with much more negative responses from students. Teachers in all schools were very disturbed by external noise. This implies a general concern of internal and external noise which may be a major contributor to disturbances and distractions. Temperature was a major concern in the classrooms, as it was both uncomfortable and uncontrollable. Students tended to report greater levels of discomfort than their teachers. None of the students commented on the lack of daylight. Conflicting results were obtained in the assessment of group work areas, individual study spaces, noise levels and toilets. Students felt that there were few provisions for individual learning styles, that noise levels in classrooms 
were too high and the toilets were extremely unpleasant. The teachers did not rate these so negatively.

Students and teachers also agreed in terms of ratings of individual Schools, for example in School B, both teachers and students felt that storage, art room, music room and display were satisfactory and adequate but both groups complained of uncomfortable thermal conditions. Teachers and students in Schools $\mathrm{A}$ and $\mathrm{M}$ were generally dissatisfied with factors such as inadequate storage, space for group work or individual study, no provision for wheelchair users, inadequate art rooms, music rooms, poor landscaping and unpleasant toilets. They also felt there was high noise levels and poor ventilation throughout the school.

Although the POE process detected many similar concerns on particular factors such as lack of flexibility within learning areas, students and teachers perceived comfort factors differently within classrooms. Results revealed that acoustics and class density were major concerns amongst students but teachers felt good lighting and temperatures were more important. Noise was a recurrent concern for the students within various areas including classrooms, dining room, music room, plays areas and they were generally disturbed by external noise. This indicates that children are particularly sensitive to noise and are easily distracted. This would suggest that it is essential that acoustic treatment be applied to absorb reverberations within classrooms and locations re-considered to prevent disturbances. High density (crowded) classrooms was also another concern amongst students and may explain why students experienced in some classrooms, level of aggression and noise. Students require a certain level of physical movement and freedom. Appropriate classroom sizes are an essential factor in resolving this issue in school design and must be accommodated during the early planning stages.

The POE also suggested that students felt a certain degree of privacy was necessary but teachers were more concerned with flexibility and variety in classrooms to accommodate multiple user needs. The assessment results confirmed this and allowed specific areas to be identified that were missing such as lecture-based areas, project-based areas, reading corners, and wet areas which the POE could not identify.

The need for privacy suggested by students in the POE implies the importance of a child's need to retreat or a place where they can work at their own pace. The need for variety and flexibility implies teachers recognize that students have multiple levels of intelligence and abilities and classrooms need to accommodate this factor.

The assessment clearly indicated poor functionality and inadequacy in various spaces. However the POE results suggested many students were still satisfied with the facilities (perhaps because they had not experienced anything else, or they did not see the school in the same way as the assessor). It was observed that children felt that classrooms were their least favourite place to be and were happy to be outside the classroom. Despite poor conditions within areas such as the library, dining area and play areas all of which scored low on the assessment and the teachers' evaluation but high on the students' evaluation, such spaces gave students a chance to socialize and the opportunity to take a break from class. This may imply that students require and welcome opportunities for change and variety to enhance their learning environment. It can also suggest that confining a child within a classroom for several hours may go against a child's natural tendency to be active. Allowing a child the opportunity to leave the confines of a room may assist in preventing boredom and assist in keeping students involved and active. According to the literature, allowing students the ability to choose how and where they study gives them a certain amount of control and ownership. In turn, students become more enthusiastic about learning. Considerations must be made to ensure that the design of schools allows for choice and change by providing a variety of learning spaces.

\subsubsection{Parent issues}

The scores from the questionnaires completed by parents were on average $28 \%$ higher than those from teachers. The parents were not able to comment in a knowledgeable way on much of the school environment. However, in School B, they agreed with teachers that the building was aesthetically pleasing, ageappropriate, spacious, and had good circulation, with clear and visible signage that was easy to follow, and with adequate display areas for student work and achievements. The parents also felt that the building was well landscaped, with good lighting and ventilation. Conflicting responses were observed in relation to temperature and acoustics.

Parents are stakeholders in the school and should be concerned about the environment in which their child is educated. However, as in the UK a lot of effort had to be spent in getting parents to participate in 
the survey. Given the variation in the results, it may be that such effort is misplaced.

\section{Discussion and conclusions}

A combination of expert checklists and POEs were used to assess the educational facilities of three schools in Saudi Arabia. Although these schools may be considered to be at the higher end of educational provision, the quality of the facilities varied significantly.

The four checklists provided a systematic appraisal of the teaching facilities. The CEFPI Adequacy Assessment and Lackney's Class Modalities were used to identify the presence of key classroom elements. For example, CEFPI revealed that the classrooms lacked variety and flexibility and the Class Modalities checklist revealed that they provided limited support for performance based, seminar-style, and hands-on project areas. Nair and Fielding's 28 Design Patterns revealed the absence of other areas such as shared areas, quiet spaces, casual eating areas, activity hubs, soft furnishings, outdoor learning areas and learning studios. The DASE checklist also enabled an assessment of those areas to be made (rather than just noting their presence or absence). Some limitations were noted in terms of the rating scales and the cultural relevance of some issues.

The checklists provided a context for the POE, and allowed accurate recommendations to be made. They enabled a picture to be built up of how the different areas of the school related to each other, and where more logical restructuring of rooms might be possible, e.g. the relationship between different types of learning environments, the adhoc spatial relationships between administrative offices, classrooms and clinics, noisy and quiet areas. Importantly, the POE enabled students' views to be captured, and instances identified where their views were different from their teachers. This indicates that teachers should not stand as proxies for children, as they may not view the environment in the same way, and also that children are able to comment in a meaningful and sophisticated way about their environment.

The results from the POE agreed with those obtained from the checklists, providing detailed information of users' views of the facilities, and environmental factors (such as temperature and acoustics) and where there were differences in perspectives. The checklists were useful in interpreting the POE state- ments (for example, when a facility was rated poorly or adequate when it was in fact missing!), but the POE provided more details of the implications of design for teaching and learning.

Considering the use of the POE for parents, the return rate was small across all schools despite repeated efforts to gather questionnaires. Also, parents were not able to comment reliably on a lot of the school environment. Although the low response rate for this group was clearly exacerbated by the Saudi culture, similar issues were found in Newman's (2009) original survey. The viewpoint of parents is important, however, given their noted lack of willingness to engage in school led activities and the quality of feedback, one must question whether resources directed in this area are worthwhile. When their responses were compared to those of other groups, they tended to rate more favourably.

Combining the methods ensured that an independent assessment was made of the facilities that could contextualize the comments derived from the POE. The methods enabled detailed recommendations to be made to each school in terms of short-term improvements such as colour change, signage, lighting, landscaping, and furnishings. It is hoped that the method will form the foundations for post occupancy evaluation in Saudi Arabia.

The results have illustrated that young students take notice of their environment and can comment on it when the request is couched in terms they understand. The extent to which they understand the importance of different types of educational facilities needs to be considered further, suffice it to say that they understand the importance of quiet areas , working in groups and sometimes alone.

The material used in the study was translated from a UK context, although some adjustment was made for cultural differences, further work needs to be conducted on the effects of different teaching styles, and also the influence of the climate and social/cultural norms on the design of the facilities.

\section{Acknowledgements}

All research was completed by Sana Omari as part of an MRes at Coventry University, under the supervision of Andree Woodcock and Tim Ball. We would like to thank all schools who took part in the research 


\section{References}

[1] H. Frumkin, R. Geller, J. Nodvin, Safe and Healthy School Environments. London: Oxford University Press, 2007

[2] M. Newman, P. Dunham and A. Woodcock, How children perceive and use the primary school environment, Contemporary Ergonomics, London: Taylor and Francis,2007, 235-240

[3] M. Newman, Post Occupancy Evaluation of Primary Schools: A multi-stakeholder Perspective. PhD Thesis, Coventry University, Unpublished doctoral thesis, 2010

[4] H. Sanoff, C. Pasalar and M. Hashas, School Building Assessment Methods. National Clearing House for Educational Facilities, www.edfacilities.org/pubs/sanoffassess.pdf, 2001

[5] C. Zimring and T. Rosenheck, Getting it right the second or third time rather than the sixth or seventh. California Department of General Services. DGS POE program http://www.poe.dgs.ca.gov/More+Info/FFCTalk+.htm, 2001

[6] J.A. Lackney, The State of Post Occupancy Evaluation in the Practice of Educational Design. Paper presented at the Annual meeting of the Environmental Design Research Association (EDRA) held 3-6 July 2005 at Edinburgh, Scotland [online] available from http://schoolstudio.engr.wisc.edu, 2001 [12th October 2009]
[7] K. Tanner, The School Design Assessment Scale: Validity, Reliability and Weights, School Design and Planning Laboratory, University of Georgia [online] available from $<$ http://www.coe.uga.edu/sdpl/sdpl.html>,1999, [28th April 2010]

[8] CEFPI School Building Association (n.d) 'Elementary School post-occupancy evaluation form' [online] available from < http://web.archive.org/web/20071214093401/http://www.cefpi .org/creatingconnections/\#14> [30th Dec 2009]

[9] CEFPI School Building Association (n.d) Educational adequacy assessment form' [online] available from http://www.edfacilities.org/search/index.cfm> [30th April 2010]

[10] R. Fielding and N. Prakash, The Language of School Design: Design Patterns for 21st Century Schools. Minneapolis: The National Clearinghouse for Educational Facilities,2005

[11] J.A. Lackney, "New approaches for school design", The Sage Handbook of Educational Administration [online] 50637 ,

$<$ http://edweb.sdsu.edu/schoolhouse/documents/Improvingthe $\% 20$ Physcial $\% 20$ and $\% 20$ Social $\% 20$ Environment $\% 20$ of $\% 20 \mathrm{~S}$ chool.pdf> 2005, [8th November, 2009] 